\title{
THE NUMERICAL MODELLING OF THE EFFECT OF OCCURRENCE DURATION ON THE WATER LEVEL DIFFERENCE FOR THE BOSPHORUS STRAIT
}

\author{
Mehmet N. Öztürk ${ }^{1}$ and Yalçın Yüksel ${ }^{1}$
}

The straits connecting two large water bodies show highly strong and stratified currents related to meteorological, morphological and hydrodynamic conditions. The Bosphorus is a long sea strait connecting the Black Sea and the Sea of Marmara. In general there is a two layer current system in the Bosphorus, which is largely determined by conditions at the Black Sea. The upper layer flows from the Black Sea to the Sea of Marmara caused by decline in surface elevation between the Black Sea and Sea of Marmara. The lower layer flows in opposite direction caused by the density difference which is due to the difference in salinities.

In this study the effect of occurrence duration of water level difference $(\Delta \mathrm{h})$ on the Bosphorus current structure was modelled using a three dimensional hydrodynamic modelling approach. The approach is based on an unstructured flexible mesh and uses a finite volume solution technique, which provides an optimal flexibility while retaining an efficient numerical solution. The meshes are based on linear triangular elements. An uniform rectangular channel which has simple geometry compare with Bosphorus was used for modelling. The channel has Bosphorus average values in dimensions. It is $900 \mathrm{~m}$ in width, 32,000 $\mathrm{m}$ in length and $64 \mathrm{~m}$ in depth. The constant salinty boundary conditions were described at the open boundaries corresponding Marmara and Black Sea boundaries and no water level difference as initial surface elevation. Using $k-\varepsilon$ turbulence choice and hydrostatic pressure assumption, the two different occurrence duration for the same increase at the water level difference were modelled. In the first case the increasing of the duration for the water level difference described shorter than the second case. The model resultsand measurements show that, in the first case onelayered flow becomes dominated whole the channel flow, on the other hand in the second case two-layered flow persisted.

Keywords: stratified flow; the Bosphorus; hydrodynamic modeling of stratified flows; Mike 3D FM

\section{Introduction}

The Bosphorus is a long, narrow and shallow waterway between the Black Sea and the Marmara Sea (Figure 1). It has very small depth/lenght ratio making its flow structure more complex than other similar straits (the Gibraltar, the Dardanelles) on the world. Its lenght is about $31 \mathrm{~km}$ and its width varies from 0.7 to $3.5 \mathrm{~km}$ at the surface. As to its average depth, different researchers took into account several depths which vary from $20 \mathrm{~m}$ to $60 \mathrm{~m}$ (Zaremba et al., 2003). But there are many pit which depths vary between 100-120 $\mathrm{m}$. There are also two sills at the southern entrance $(2 \mathrm{~km}$ away from the entrance where depth varies between $-28 \mathrm{~m}$ and $-34 \mathrm{~m}$ ) and the northern entrance (lying like a narrow and long channel at the Black Sea entrance).

The Bosphorus consists of two oppositely flowing currents: the upper layer flows from the Black Sea to the Sea of Marmara caused by decline in surface elevation between these two seas and the lower layer flows in opposite direction caused by the density difference which is due to the difference in salinities between the Sea of Marmara and the Black Sea.

The Black Sea is a landlocked basin. The sum of the run off and precipitation towards the Black Sea is more than the evaporation. The water excess is balanced by an outflow throught the Bosphorus (Ünlüata et al., 1990; Özsoy et al. 1996). The water level difference between two ends of the strait is the main forcing for the upper layer flow.

In general the water level at the Black Sea mostly was higher than that of the Marmara Sea. The difference of the water level has four main components. These are due to wind set up, meteorological atmospheric pressure, tide and long term hydrological changes (river discharges). The first three water level changes are due to short term effects but the last one is due to long term effects which represent the seasonal variations (Yüksel et al., 2008). The fluctuations of the water level difference caused by long term effects are more stable than caused by the short term ones.

On the other hand because the evaporation of the Sea of Marmara is grather than the Black Sea, a density difference caused by salinity difference occurs between these two seas. The average salinity of the top layer is $18 \mathrm{ppt}$ at the exit from the Black Sea. This value gradually increases and reaches $23-25 \mathrm{ppt}$ at

\footnotetext{
${ }^{1}$ Yıldız Technical University, Department of Civil Engineering, Coastal and Harbor Engineering Laboratory, Barbaros Cad., Yıldız, İstanbul, Turkey
} 
the entrance of the Marmara Sea. For the lower layer, the average salinity is $38 \mathrm{ppt}$ in the Marmara Sea at the southern end of the Bosphorus, dropping to $33 \mathrm{ppt}$ at the northern sill (Oğuz et al., 1990)
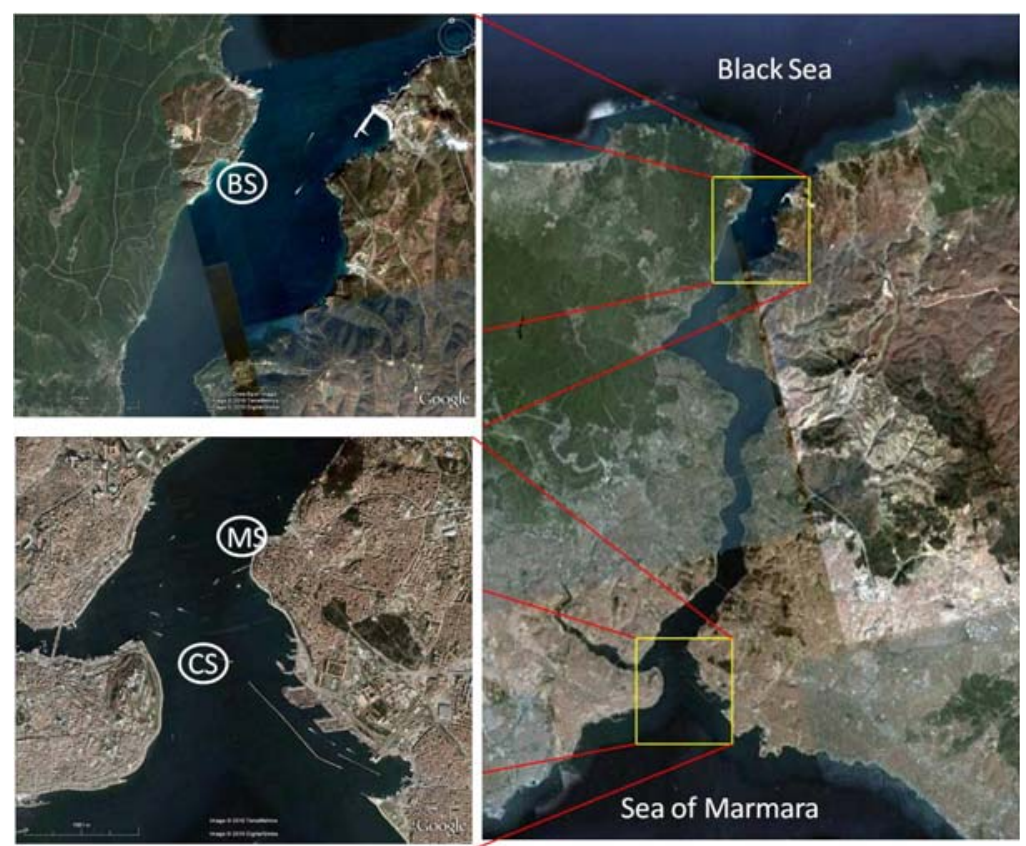

Figure 1 Ariel view of the Bosphorus and the location of water level stations (MS, BS) and current station (CS) in the strait

\section{The Relation Between the Occurrence Duration of the Water Level Difference and Current Structure at the Bosphorus from Measurement}

To examine the occurrence duration of the water level difference on the Bosphorus flow structure, two different cases were taken into consideration. At the first case, as seen in Table1, the water level difference $(\Delta \mathrm{h})$ of $0.20 \mathrm{~m}$ between the Black Sea and the Sea of Marmara occurred at the end of 15 hours. But at the other one the same water level difference occurred at the end of 84 hours. The water level difference, which was measured at stations BS and MS by the Ministry of Transportation in 2005 (see Fig. 1), between Black Sea and Sea of Marmara increases from $0.20 \mathrm{~m}$ to $0.40 \mathrm{~m}$ at both cases (Table 2). The cases represent maximum water level difference condition for their measurement period.

\begin{tabular}{|l|l|l|l|l|l|}
\hline \multicolumn{7}{|c|}{ Table 1 Water level characteristics of the two cases } \\
\hline Case & \multicolumn{2}{|c|}{ Water level difference } & $\begin{array}{l}\text { Period } \\
\text { (hour) }\end{array}$ & $\Delta \mathrm{h}(\mathrm{m})$ & Explanation \\
\cline { 2 - 5 } & Start & Finish & 15 & 0.20 & $\begin{array}{l}\text { The water level difference } \\
\text { between BS and MS. }\end{array}$ \\
\hline $\begin{array}{l}\text { Case1 } \\
\text { (Marh 2005) }\end{array}$ & $10.03 .0523: 00$ & $11.03 .0514: 00$ & 15 & 0.20 & \\
\hline $\begin{array}{l}\text { Case2 } \\
\text { (August 2005) }\end{array}$ & $27.08 .0503: 00$ & $30.08 .0515: 00$ & 84 & \\
\hline
\end{tabular}

Figures 3 and 4 show the North-south (N-S) current profile at the CS at the beginning and end of the Case 1 respectively. CS is a current station (Fig. 1) and it was located at $-25 \mathrm{~m}$ close to the southern entrance of the Bosphorus. Current speed and direction measurement was carryied out by supporting of the Ministry of Transportation at CS in 2005.

From the figures, one can easily see that at the begining of Case 1 there is oppositly flowing flow in the strait. But in consequence of increase for the water level difference in a short time, there is only unidirectional homogenous flow at the end of the Case 1. The extreme weather conditions (i.e. storms) may 
have caused the water level conditions such as Case 1 in the Bosphorus. As before mentioned, that kind of effect is called as short-term effects. The negative values indicates northern (upper layer) velocities, while positives are southern (the lower layer) in Fig. 3.

Figures 5 and 6 show the variation of the N-S current throught depth at CS station at the beginning and end of the Case 2. Two-layered flow structure was still existed at the end of the Case 2 which was different from the Case1. The increase of water level difference from $0.2 \mathrm{~m}$ to $0.4 \mathrm{~m}$ took place after 84 hours $(3.5$ days) for the Case 2. Compare to the Case 1, the same increase on the water level difference took long time for the Case 2. Thus the upper layer, which is orginated from water level difference, couldn't dominate the whole current profile in the Bosphorus. That's why the lower layer flow, which is driven from difference in densities between two seas, resisted to the upper layer layer at the end of the Case 2.

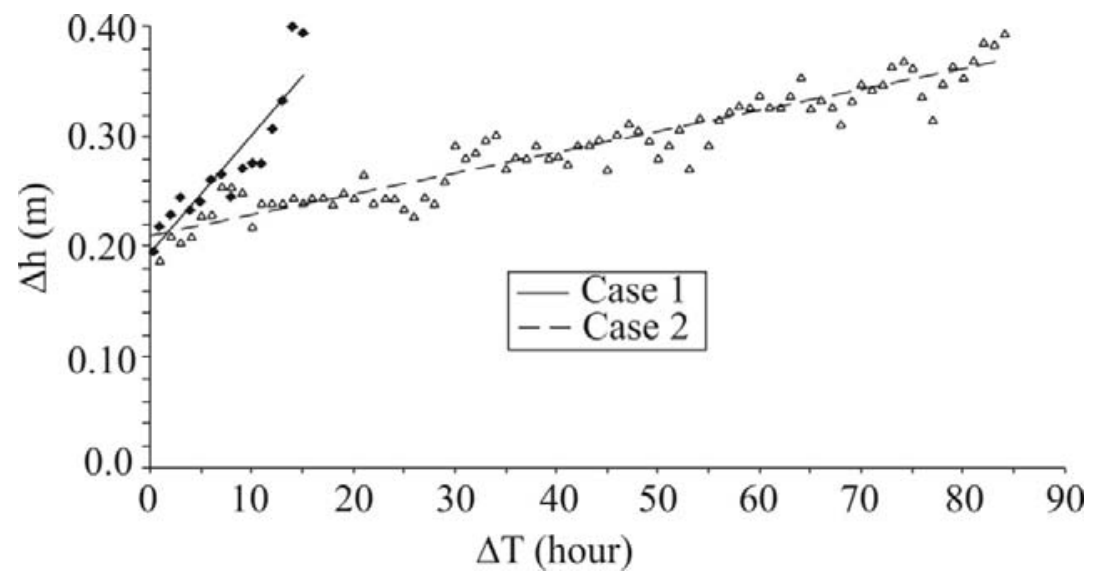

Figure 2 The variation of water level difference at Case 1 and Case 2

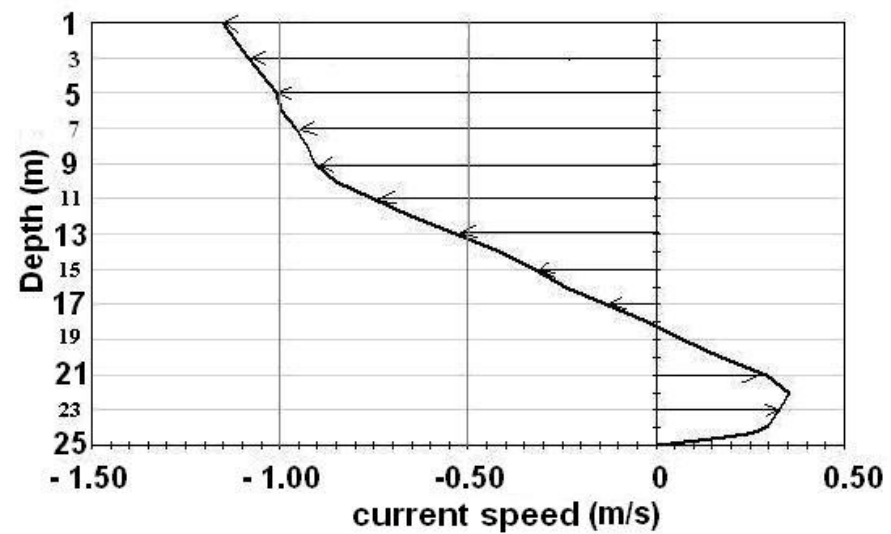

Figure 3 Two layer flow pattern at the beginning of Case 1 (left hand side is the Sea of Marmara and right is the Black Sea side) 


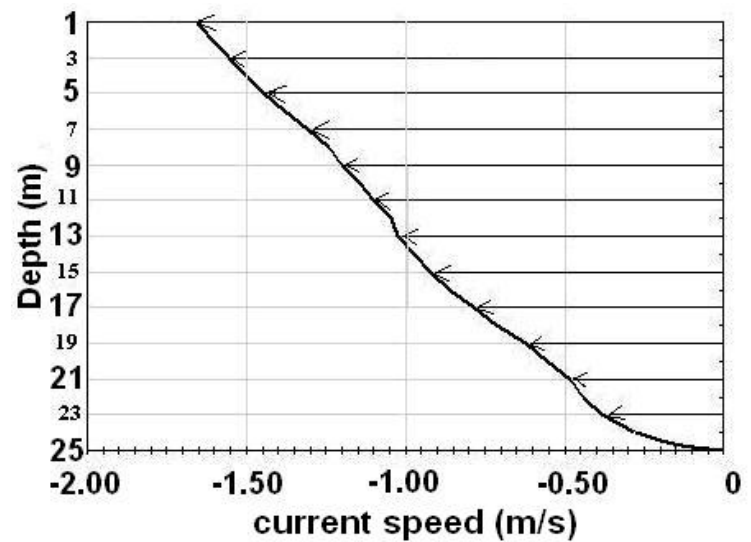

Figure 4 One-layer flow pattern at the end of Case 1 (left hand side is the Sea of Marmara and right is the Black Sea side)

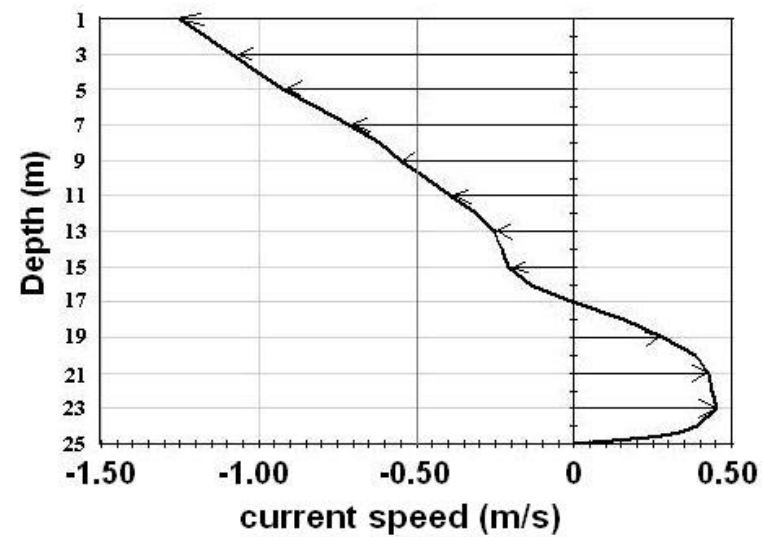

Figure 5 The current profile at the beginning of Case 2 (left hand side is the Sea of Marmara and right is the Black Sea side)

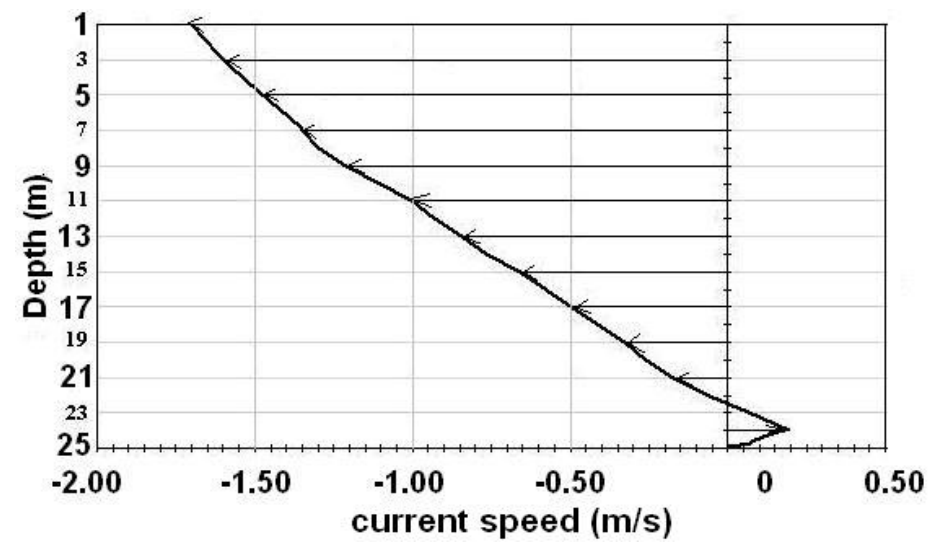

Figure 6 The current profile at the end of Case 2 (left hand side is the Sea of Marmara and right is the Black Sea side) 


\section{Modelling the Duration of Water Level Difference on the Flow Structure}

At the modelling stage, Mike 3 Flow Model FM was used to model the effect of the water level duration on the Bosphorus Strait flow. MIKE 3 Flow Model (FM) is a modelling system based on a flexible mesh approach. The modelling has been developed by DHI (Danish Hydraulic Instutue) for applications with in oceanographic, coastal and estuarine environments. The system is based on the numerical solution of the three-dimensional incompressible Reynolds averaged Navier-Stokes equations invoking the assumptions of Boussinesq and of hydrostatic pressure. Thus, the model consists of continuity, momentum, temperature, salinity and density equations and is closed by a turbulent closure scheme. In the horizontal domain both Cartesian and spherical coordinates can be used. The free surface is taken into account using a sigma-coordinate transformation approach.

The spatial discretization of the primitive equations is performed using a cell-centered finite volume method. The spatial domain is discretized by subdivision of the continuum into non-overlapping element/cells. In the horizontal plane an unstructured grid is used while in the vertical domain a structured discretization is used. The elements can be prisms or bricks whose horizontal faces are triangles and quadrilateral elements, respectively (Fig. 7). For the time integration a semi-implicit approach is used where the horizontal terms are treated explicitly and the vertical terms are treated implicitly.

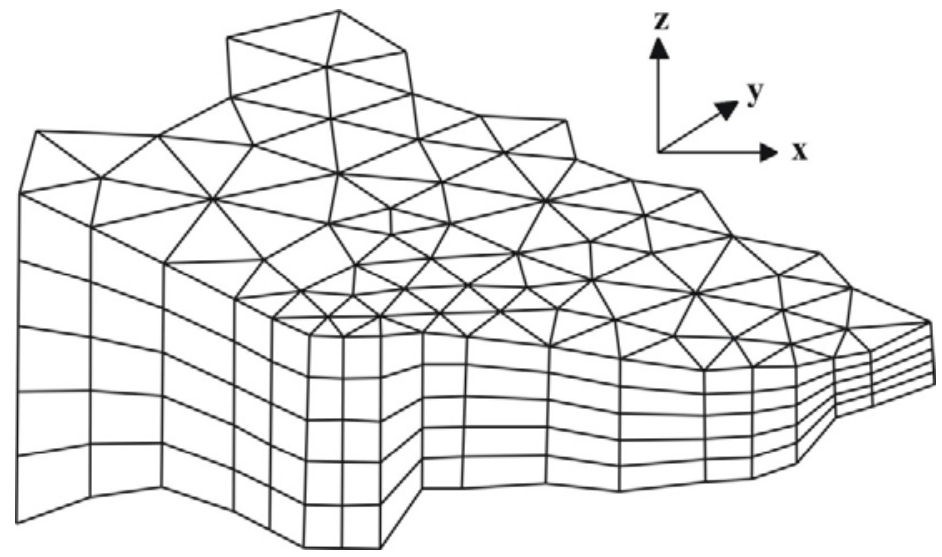

Figure 7 The mesh structure of Mike 3 Flow Model FM

As the model geometry very simple rectangular channel, which has the average dimensions of the Bosphorus, was used (Fig. 8). It is $900 \mathrm{~m}$ in width, 32,000 $\mathrm{m}$ in length and $64 \mathrm{~m}$ in depth The model domain was constitute from 2902 triangular mesh elements in the horizontal plane. As the vertical resolution 30 equidistant layers were described. Fig. 8 shows the schmatic view and the mesh structure of the channel. The simulation time of the model was determined as 200000 time step with time step interval $(\Delta \mathrm{T})$ of 1 second. Thus the simulation time for the model would equal to 200000 seconds. Turbulence structure of the strait in horizontal an vertical plane was calculeted using Smagorinsky and k- $\varepsilon$ turbulence formulation respectively. As it is considered the roughness plays important role on the lower layer flow and has a quite high value depending on the strait bottom shape the roughness heigh $\left(\mathrm{k}_{\mathrm{s}}\right)$ of the bed was selected $0.30 \mathrm{~m}$ of the maximum value advised by the model. 


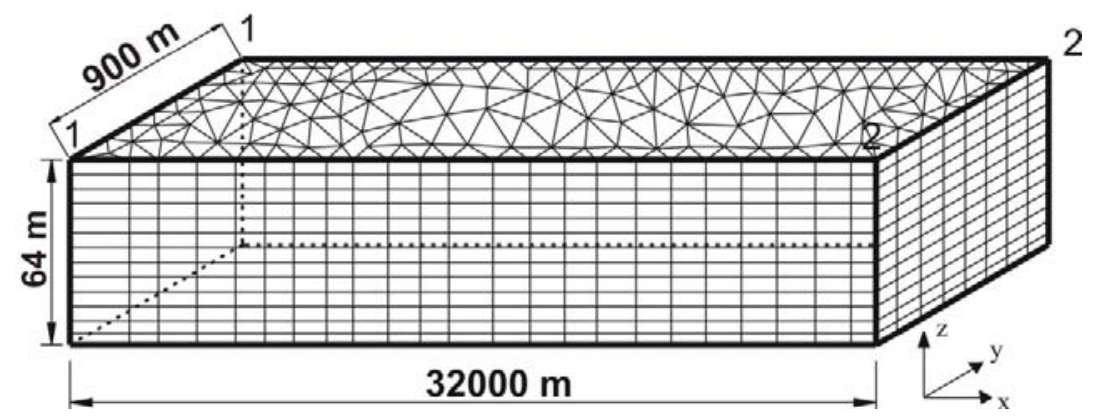

Figure 8 The schematic view and mesh structure of the model domain

The salinity boundary conditions at 1-1 and 2-2 boundaries, which represent the Sea of Marmara and the Black Sea respectively, 38 and 18 ppt as its average values of Sea of Marmara and Black Sea. It is also described an initial salinity as 18 ppt throught the rectangular channel.

Using the hydrodynamic model parameters mentioned above, two different models were run. No initial water level difference was described between the open boundaries for both models. Because the barotropic forcing driving by water level difference is more stronger than baroclinic one driven by difference in densities between two boundaries, there is no water level difference described between two boundaries of the models for the first 60000 seconds (Fig. 9). Then the water level difference between 2-2 and 1-1 boundaries was icreased from 0 to $0.40 \mathrm{~m}$ in 80000 (22.2 hours) seconds in model 1 . But the same icrease was implemented in 120000 seconds in model 2. After these same increases with different duration, the water level differences kept as $0.40 \mathrm{~m}$ at the rest of the simulation time.

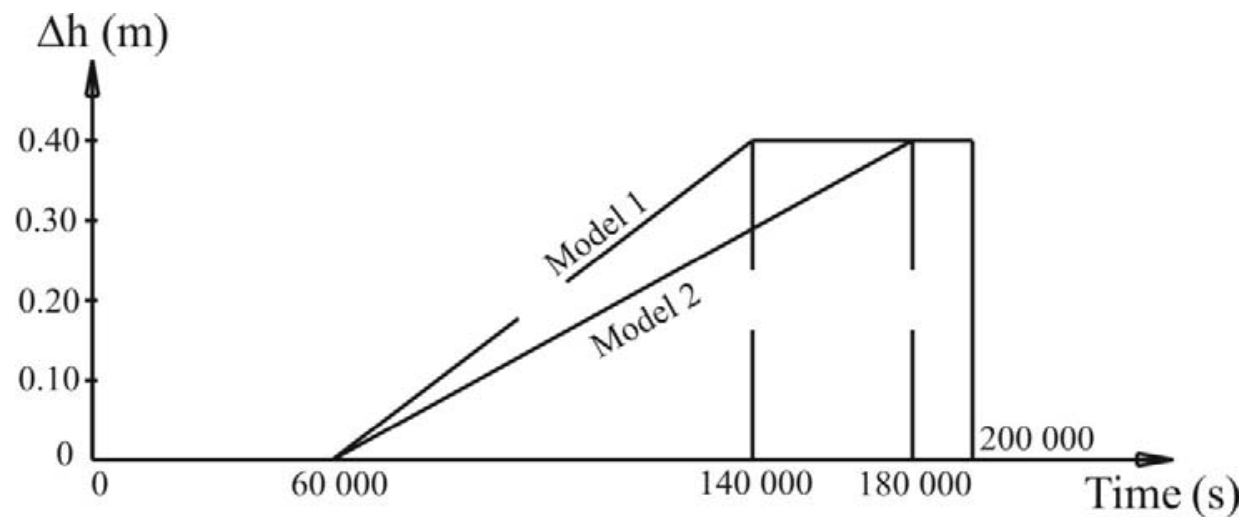

Figure 9 The water level bondary conditions for Model 1 and 2

Figures 10 and 11 show the $u$ velocity (velocity component in $\mathrm{x}$ direction) profile at mid section of the rectangular channel in model 1 at the time step of $100000 \mathrm{~s}$ and $140000 \mathrm{~s}$, at which $\Delta \mathrm{h}$ is $0.20 \mathrm{~m}$ and 0.40 $\mathrm{m}$ respectively. It is clearly seen from the figure that at the beginnig of the water level increase period of $0.20 \mathrm{~m}(100000 . \mathrm{s})$, there is two layered flow structure at the mid channel $(\mathrm{x}=16000 \mathrm{~m})$. But at the end of the period $(\Delta \mathrm{h}=0.40 \mathrm{~m})$, after increasing at the water level difference, the upper layer flow dominated flow field throught the depth at that channel section. The surface velocity starts to increase from $1.7 \mathrm{~m} / \mathrm{s}$ and reachs to $2.7 \mathrm{~m} / \mathrm{s}$.

Figures 12 and 13 show the $u$ velocity profile at mid section of the rectangular channel for the model 2 at the time step of $120000 \mathrm{~s}$ and $180000 \mathrm{~s}$. In contrast to model 1 , both at $120000 \mathrm{~s}(\Delta \mathrm{h}=0.20 \mathrm{~m})$ and at $180000 \mathrm{~s}(\Delta \mathrm{h}=0.40 \mathrm{~m})$, a two layer flow still exists at the mid section of the channel. 


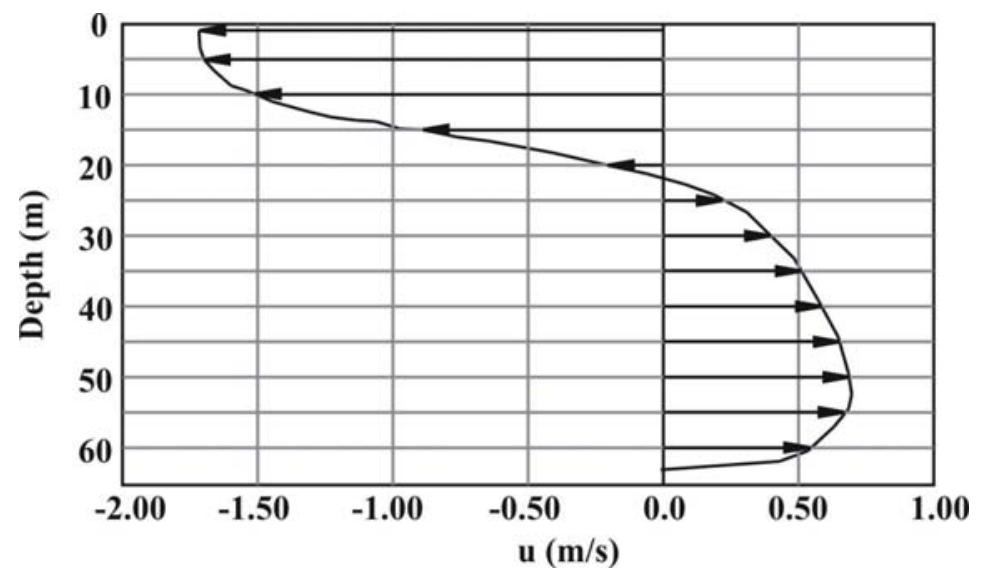

Figure 10 The $u$ velocity profile throught depth at mid section of the channel $(x=16000 \mathrm{~m}$; negative values indicate the upper layer flow, positive ones is the lower layer) at $100000 \mathrm{~s}$

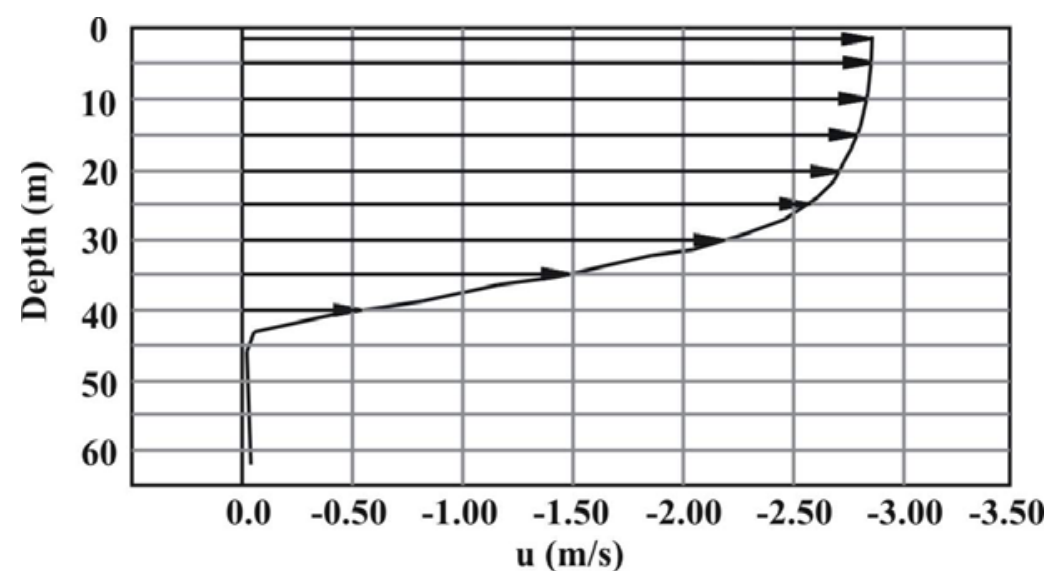

Figure 11 The $u$ velocity profile throught depth at mid section of the channel $(x=16000 \mathrm{~m}$; negative values indicate the upper layer, positive ones is the lower layer) at $140000 \mathrm{~s}$

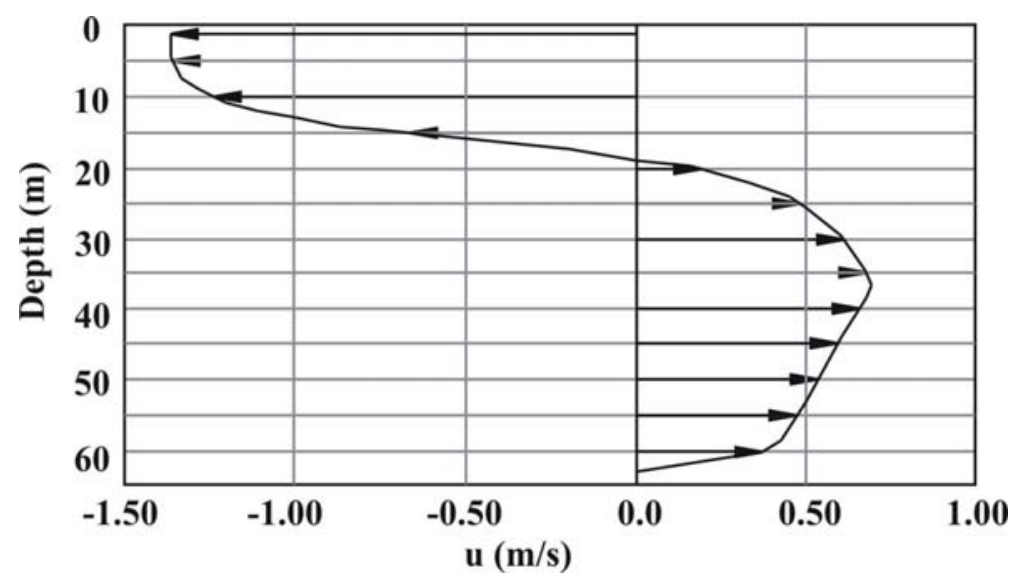

Figure 12 The $u$ velocity profile throught depth at mid section of the channel $(x=16000 \mathrm{~m}$; negative values indicate the upper layer flow, positive ones is the lower layer) at $120000 \mathrm{~s}$ 


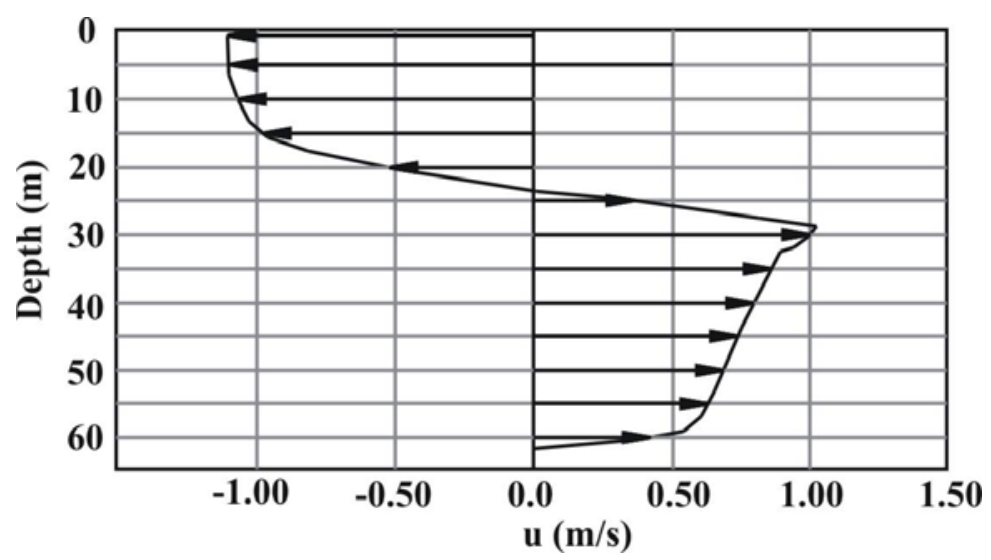

Figure 13 The $u$ velocity profile throught depth at mid section of the channel $(x=16000 \mathrm{~m}$; negative values indicate the upper layer, positive ones is the lower layer) at $180000 \mathrm{~s}$

\section{Discusions and Conclusions}

Using Mike 3 Flow Model (FM) which is a three dimensional modelling system based on a flexible mesh approach, the effect of the occurence duration of the water level diffrence on the Bosphorus current was modelled. For the same water level increase, two different cases were studied. At the beginning of the both cases there were two layer flow structure in the channel. But at the end of the cases two different flow structures were appeared. At the end of the first case that had the shorter duration of the water level increase, there was one layered flow but at the end of the second one still two layered flow structure had been existed. Due to the longer duration, in the second case the upper layer couldn't dominate whole channel flow. The model results compared to measurement qualitatively. It is seen that the flow structure of the models was similar to the measurements.

\section{Recommendations}

In this work very simple rectangular channel geometry was used for modelling the Bosphorus flow. But there are two sills and a contraction which effect the strait flow mainly in the Bosphorus. It should be used more sophisticated model domain including these geometrical features.

As the meteorological condition (wind set up and air pressure) is effective parameters on the water level behavior and the upper layer flow especially, It should also be described meteorological parameters as input parameters to the model.

\section{References}

Oğuz, T., Özsoy, E., Latif, M. A., Sur, H. İ. and Ünlüata Ü. 1990.Modeling of Hydraulically Controlled Exchange Flow in the Bosphorus Strait, Journal of Physical Oceanography, Vol 20, No 7, July.

Özsoy, E. Latif, M.A., Sur, H.I. and Goryachkin 1996. A review of the exchange flow regime and mixing in the Bosphorus Strait, Bulletin de 1'Institut Oceanographique, Monaco, $\mathrm{n}^{\mathrm{o}}$ special, CIESM Science Series nu 2, pp187-204.

Ünlüata, Ü., Oğuz, T., Latif, M.A. and Özsoy, E. 1990. On the Physical Oceanography of Turkish Straits, The Physical Oceanography of Sea Straits, Pratt L.J. ed, NATO/ASI Series, Kluwer, Dordrecht, 25-60.

Yüksel, Y., Ayat, B., Öztürk, M.N., Aydoğan, B. Güler, I., Çevik, E.O., Yalçıner, A.C. 2008.Responses of the stratified flows to their driving conditions, Ocean Engineering, 35, p. 1304-1321

Zaremba, L.J., Lawrence, G.A., Pieters, R. 2003. Frictional two-layer Exchange flow, J. Fluid Mech., vol. 474, pp. 339-354. 